\title{
Experimental Investigation on the Failure Behavior of Carbon Fiber Reinforced Polymer (CFRP) Strengthened Reinforced Concrete T-beams
}

\author{
Utomo, J. ${ }^{*}$, Khusyeni, M.N. ${ }^{2}$, Partono, W. ${ }^{3}$, Han, A.L. ${ }^{3}$, and Gan, B.S. ${ }^{4}$
}

\begin{abstract}
Carbon Fiber Reinforced Polymers (CFRP) are widely used as external concrete reinforcement. The behavior of T-beams strengthened in shear and flexure using CFRP sheets and plates was studied to analyze the load carrying capacity and failure mode as compared to conventional concrete members. The bonding response of the plate-to-concrete was investigated by comparing a specimen with a plate anchored at the far ends, and one without anchoring. The sheets were in situ wet lay-up, the plate was pre-impregnated and pultruded during manufacturing. The test result suggested that this integrated strengthening method notably improved the load-carrying capacity. It was also demonstrated that anchoring had a positive but insignificant effect on the moment capacity and deformation. The influence of anchoring was noteworthy from the point of view that it shifted the failure mode from debonding to CFRP plate rupture. The most important factors influencing the behavior of CFRP strengthened beams are outlined.
\end{abstract}

Keywords: CFRP plate; sheet; load-carrying capacity; debonding; rupture.

\section{Introduction}

The use of Fiber Reinforced Polymer (FRP) as external reinforcement has seen a rapid evolution during the past three decades. While the first stages of the composite action between FRP and concrete were hindered by the loss of compatibility due to debonding, the majority of these issues have now been resolved. Nevertheless, the fact is that the interface between the FRP and the concrete remains the weak link in the system. When debonding problems could be overcome, FRP external reinforcement has the potential of even better load-carrying capacity, stiffness, and ductility enhancement. The compatibility between the two materials depends strongly on their mechanical properties, i.e., the stress-strain constitutive behavior in tension and compression, the Poisson's ratio and the ultimate strength and strain [1-3].

Numerous researches have been carried out on reinforced FRP concrete, the majority focused on flexure and shear. The use of FRP plates, in particular, could be found in the work of Liu et al. (2020), El-zeadani et al.

\footnotetext{
${ }^{1}$ Department of Civil Engineering, Atma Jaya Yogyakarta University, Yogyakarta, INDONESIA

${ }^{2}$ Master Program in Civil Engineering, Diponegoro University, Semarang, INDONESIA

${ }^{3}$ Department of Civil Engineering, Diponegoro University, Semarang, INDONESIA

${ }^{4}$ Department of Architecture, Nihon University, JAPAN

${ }^{*}$ Corresponding Author, Email: junaediutomo@lecturer.undip.ac.id
}

Note: Discussion is expected before November, $1^{\text {st }} 2021$, and will be published in the "Civil Engineering Dimension", volume 24, number 1, March 2022

Received 09 September 2021; revised 19 September 2021; accepted 20 September 2021.
(2019), Zhou et al. (2018), Fu et al. (2018), Zhang et al. (2017), and Bocciarelli and Pisani (2017) [4-9]. The greater number of these Carbon Fiber Reinforced Polymer (CFRP) plates were attached with epoxy resin to the concrete using the dry lay-up method. These studies have shown that the presence of FRP laminates results in a significant increase in the loadcarrying capacity of retrofitted members. A negative aspect of these CFRP plates is the greater risk of debonding if compared to the wet lay-up sheets and embedded rods and strings [7,8,10,11]. Debonding in the interface is theoretically distinguished in debonding between the CFRP plate and the resin, and the resin to the concrete. Alternate modes of failure in the interface are the rupture of concrete in shear, and vertical cracking in the concrete beneath the plates [12]. For this reason, the code limits the minimum concrete strength of a structure that effectively could be externally reinforced using CFRP. To delay the debonding process and enhance the effectiveness of the compatibility, mechanical anchor systems or a CFRP-wrapped anchor system have been used and proven to be versatile $[6,11,13]$.

This research experimentally studied the flexural behavior of T-beams externally reinforced in shear using CFRP sheets and plates to improve the loadcarrying capacity and its overall performance. The study also looked into the anchorage effect on the behavior of these plates. A conventionally reinforced specimen denoted $\mathrm{BC}$ was produced and used as reference specimen. The data of the externally reinforced members were compared to this member to evaluate the influence of external reinforcement. Two identical but CFRP reinforced beams were 
constructed using the Surface Mounted (SM) method, plate were used for flexure, and sheets were utilized as shear reinforcement. These specimens were denoted BP1 and BP2. BP2 differed from BP1 in the sense that the length of the CFRP plate was extended so that it was confined by the supports to provide additional bonding. Specimen BP1 had a shorter plate that did not reached the support contact point.

\section{Experimental Program}

\section{Material}

All external reinforcements were attached to the concrete using the SM method. While the surface mounted term refers to the relative position of the CFRP with respect to the concrete, the application system differed for the sheets and plates. The sheets were attached using the wet, and the plate the dry lay-up method. This difference originated from the characteristics of the sheets and plate; the sheets were impregnated on-site and the plates were preimpregnated (pre-preg) (Figure 1). The epoxy laminated CFRP sheet had a tensile strength $\left(f_{u l t}\right)$ of 4300 $\mathrm{MPa}$ and a modulus of elasticity $(E)$ of $225 \mathrm{GPa}$, in combination with a strain at ultimate $\left(\varepsilon_{u l t}\right)$ of 0.0191 . The individual sheets had a thickness of $0.129 \mathrm{~mm}$; one layer was used as shear reinforcement. The laminated CFRP plate had an ultimate tensile strength $\left(f_{u l t}\right)$ of $3100 \mathrm{MPa}$ and a modulus of elasticity E of 165 $\mathrm{GPa}$, in combination with an ultimate strain $\left(\varepsilon_{u u l t}\right)$ of 0.0187 . The plate had a thickness of $1.2 \mathrm{~mm}$ and a width of $50 \mathrm{~mm}$. The concrete member had a cylindrical 28 days compression strength $\left(f_{c}\right)$ of $38.4 \mathrm{MPa}$ obtained from six cylinders produced during the beam's manufacturing. The beam element was cured using wet blankets that were kept moist during the process. The conventional reinforcing steel D19 and D16 had a yield stress of $\left(f_{y}\right)$ of $433 \mathrm{MPa}$ and $416 \mathrm{MPa}$ respectively, while both materials had a modulus of elasticity (E) of $200 \mathrm{GPa}$. A summary of the material mechanical properties is presented in Table 1.

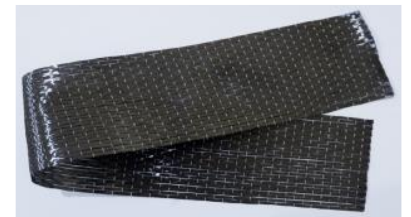

a) CFRP Sheet

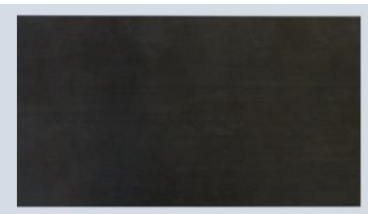

b) CFRP Plate
Figure 1. Details of CFRP Sheets and Plate

The CFRP sheets are one directionally woven black fiber produced by the high-heat setting method to achieve the fiber's stability. The major ascendancy of this type of CFRP fibers is its flexibility that makes it most suitable for use on variations of non-straight sections. The CFRP plate is manufacture pultruded and could withstand high temperatures up to 50degrees Celsius. However, the plates are sensitive to sunlight and therefore are recommended to be used inside buildings to avoid direct exposure. The plates' high rigidity limits its use as a confinement element in column and beam-column joints.

Table 1. Mechanical Properties of the Materials

\begin{tabular}{|c|c|c|c|c|c|c|c|c|c|}
\hline \multirow{2}{*}{$\begin{array}{c}\text { Concrete } \\
f_{c} \text { cylinder } \mathrm{MPa}\end{array}$} & \multicolumn{3}{|c|}{ Laminate CFRP Sheet } & \multicolumn{3}{|c|}{ Laminate CFRP Plate } & \multicolumn{3}{|c|}{ Longitudinal steel rebars } \\
\hline & $\begin{array}{c}f_{f f u} \\
\mathrm{MPa}\end{array}$ & $E_{f} \mathrm{GPa}$ & $\begin{array}{c}E f f u \\
\%\end{array}$ & $f_{f f u} \mathrm{Mpa}$ & $\begin{array}{c}E_{f} \\
\mathrm{GPa}\end{array}$ & $\begin{array}{c}\varepsilon f f u \\
\%\end{array}$ & $\begin{array}{c}\mathrm{D} 19, \\
f_{y} \mathrm{MPa}\end{array}$ & $\begin{array}{c}\mathrm{D} 16, \\
f_{y} \mathrm{MPa}\end{array}$ & $\begin{array}{c}\mathrm{E} \\
\mathrm{GPa}\end{array}$ \\
\hline 38.4 & 4300 & 225 & 1.91 & 3100 & 165 & 1.87 & 433 & 416 & 200 \\
\hline
\end{tabular}

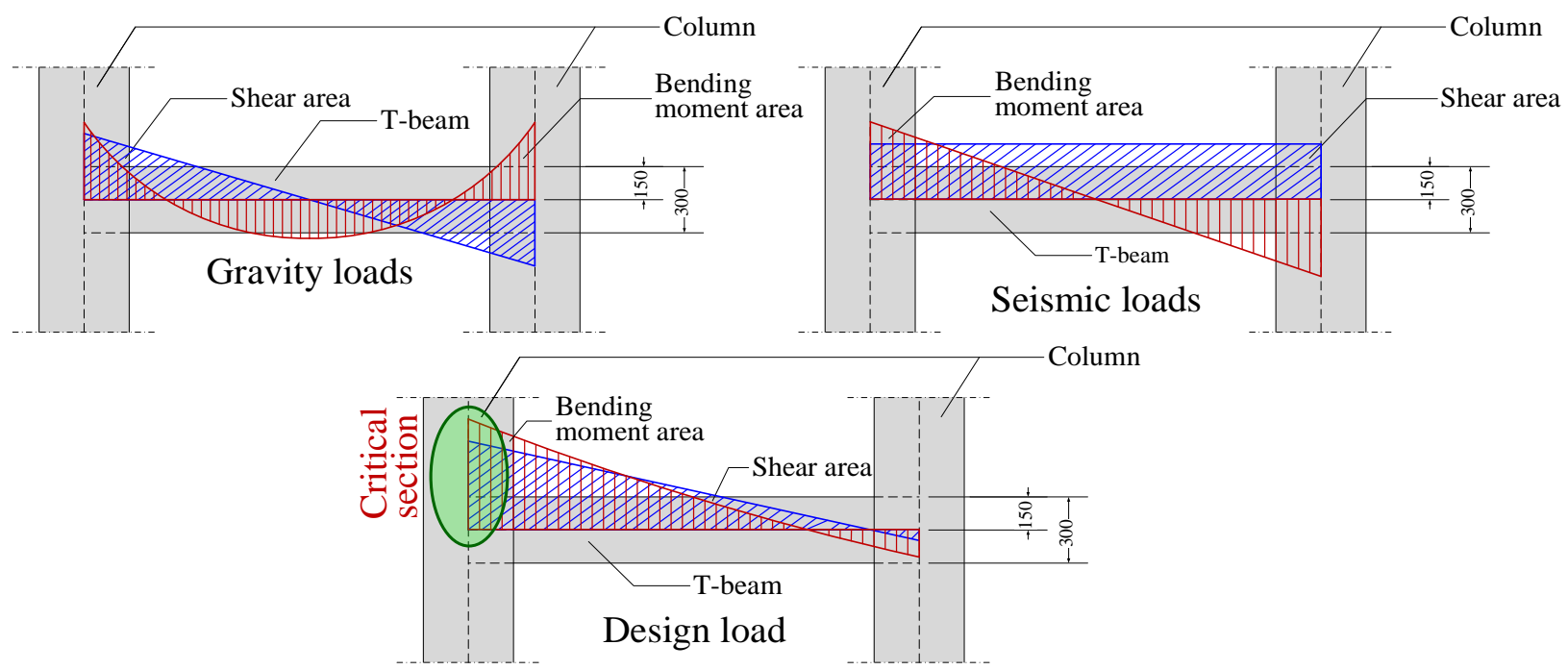

Figure 2. Loading Scheme at the Beam-column Joint 


\section{Experimental Set-up and Specimen Design}

The test program was designed to simulate the behavior of a T-beam in a frame subjected to gravity and seismic loads. The beam-column joint in a frame is subjected to combination of high bending moment and shear stresses, the flange is in tension while the web is in compression as demonstrated in Figure 2. This method was first introduced by Tudjono et al. (2018) for an identical beam-type using external CFRP sheet reinforcement [14].

To create such a condition during the laboratorybased investigation, the three-point loading system was accessed to induce high flexure and shear stresses at mid-point. Further, the T-section was reversed, and the downward loading created tension stresses in the flange and compression stresses in the web (Figure 3).

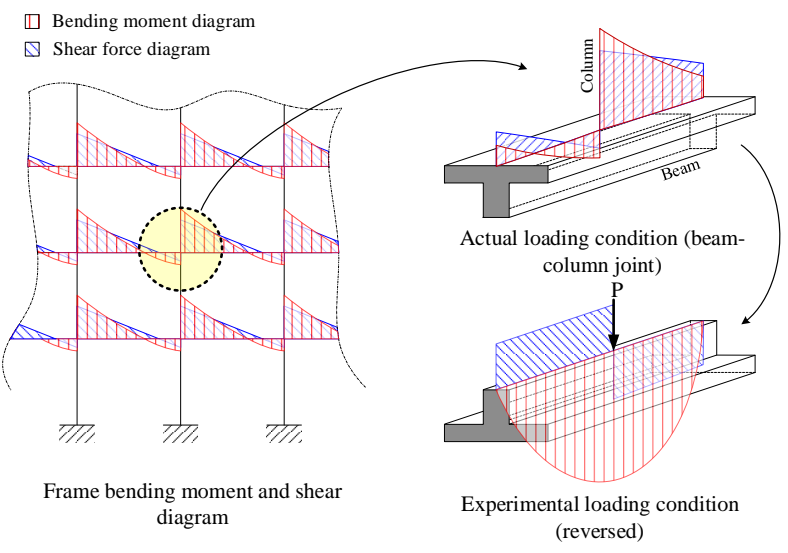

Figure 3. Experimental Simulation of Critical Section (Tudjono et al. 2018) [14]

The specimens were simply supported at a distance of $2300 \mathrm{~mm}$. The overall length of the member was 2500 $\mathrm{mm}$ (Figure 4). Figure 4 also explains the CFRP shear

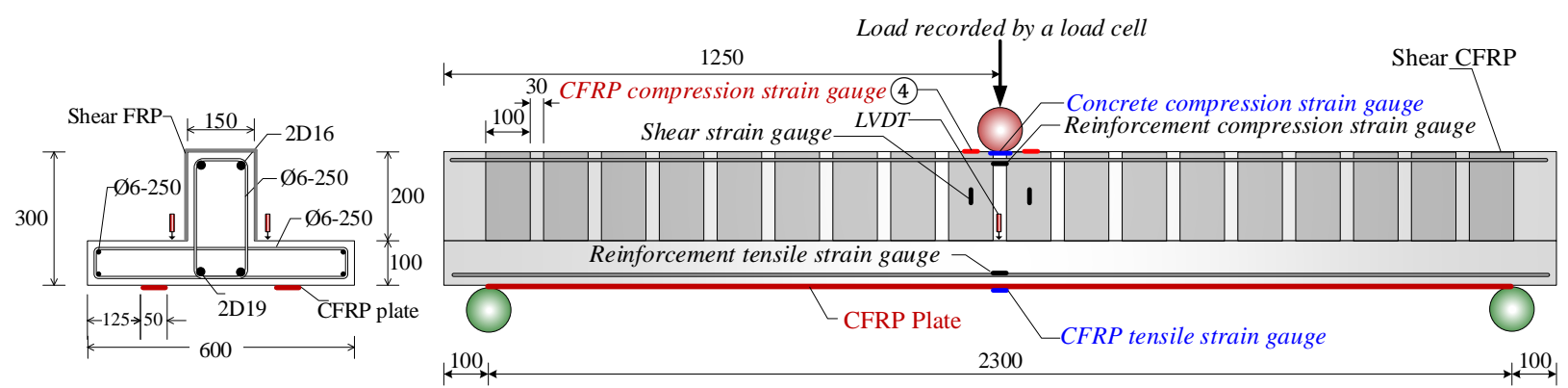

Figure 4. Specimen Details and Loading Configuration
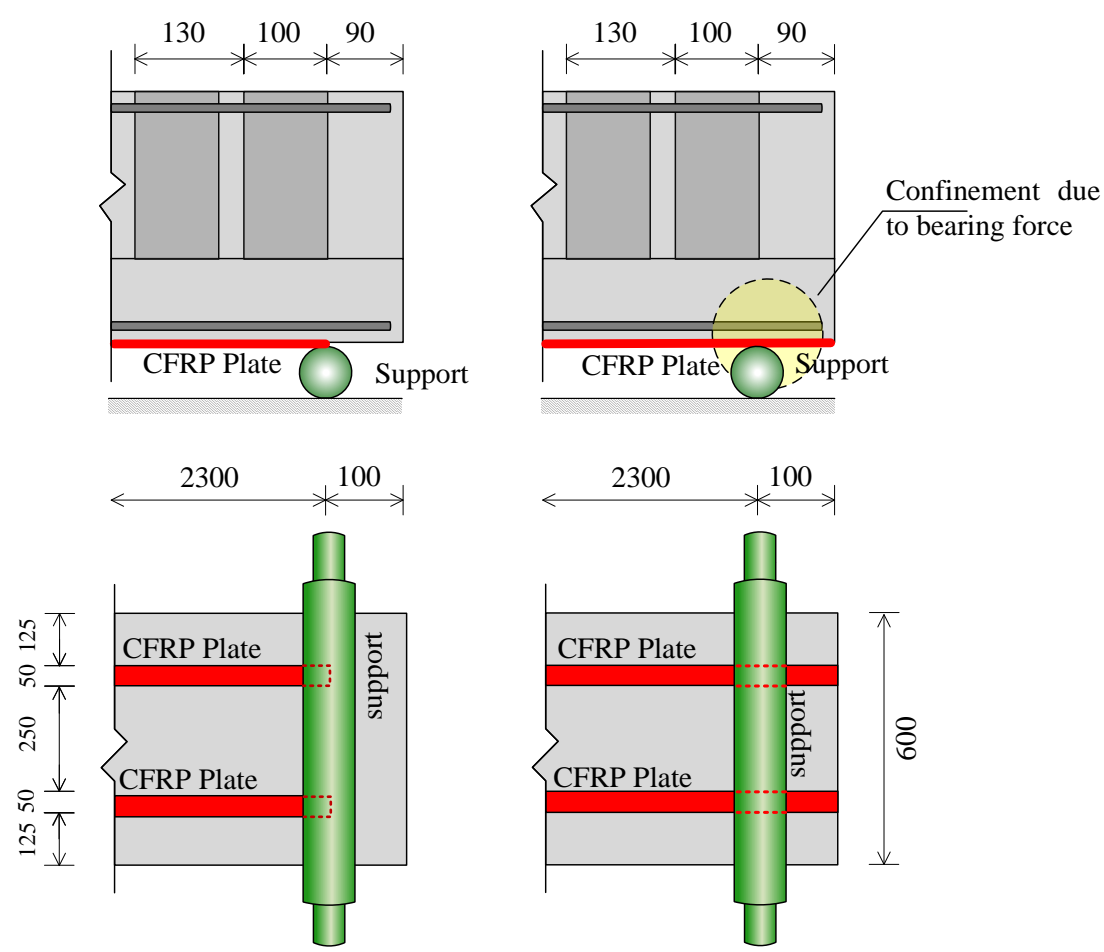

BP1

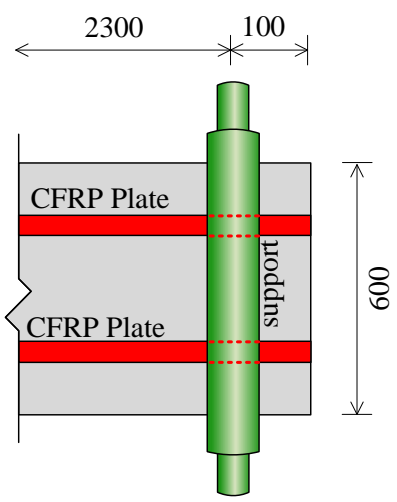

BP2

Figure 5. Plate Anchorage due to Bearing Force Confinement 
and flexure strengthening configuration. The anchorage of $\mathrm{BP} 2$ was conducted by extending the length of the CFRP plate to $2500 \mathrm{~mm}$ so that a confinement was created through the bearing force transfer from the beam to the supports as seen in Figure 5. The shear CFRP was u-wrapped around the beam's web. Since the loading created a constant stress diagram throughout the beam-length (see Figure 3), the shear reinforcement was extended along the overall length of the beam, to anticipate the shear stresses. The details of the cross-section are shown in Figure 4. While the direction of the pre-impregnated plate fiber was in good agreement with the strain behavior under loading, the shear reinforcement was not optimally utilized, since the direction of the CFRP fiber had a 45-degree angle to the principal shear stresses. A better approach would be the synchronization of the fiber direction to the shear -flow pattern. The one-point loading system induced a maximum bending moment in combination with high shear stresses at mid-span. The shear reinforcement, on the other hand, provided confinement in the concrete areas in compression.

The specimens were designed as under reinforced sections; the external CFRP strengthening was formulated to maintain this failure mode. A theoretical strain analysis was conducted to predict the strain behavior of conventional steel and to examine the calculated load-carrying capacity (Figure 6). It was shown that the ultimate strain in the D19 steel was 0.004 , whereas the yield strain was 0.002 , an under-reinforced section was thus achieved. The predicted ultimate moment-carrying capacity was found to be $149.4 \mathrm{kN}-\mathrm{m}$. The load-deformation behavior and stress-strain response of the material was monitored using precision apparatus in accordance with previous research conducted by Tudjono et al. (2015, 2018), Sapulete (2018) [14-16].

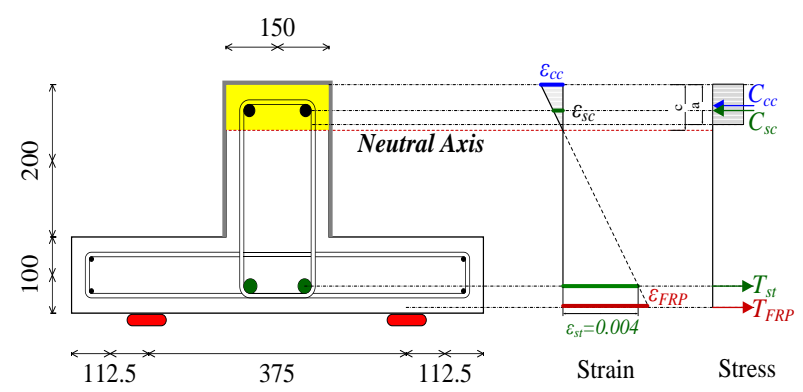

Figure 6. Theoretical Section Analysis and Strain Evaluation

\section{Specimen Preparation}

At the age of 21 days, the curing process was halted. All bonding surfaces were mechanically ground with a depth of $2-4 \mathrm{~mm}$ in accordance to the producer's guidelines to remove all the cement layers and ensure a good bond quality (Figure 7a). The areas for shear strengthening were marked, and the in-between area was covered with paper to limit the application of epoxy resin only to the location of the sheets. The sheets were attached, and a paint roller was used to put pressure on its surface so that the epoxy permeated to the surface. A second layer of resin was placed on the sheets and evenly smoothened. The CFRP was allowed to harden for 3 days.

For the plates, additional surface roughness applied by adding nail-punched evenly distributed holes with a depth of 3-5 $\mathrm{mm}$ followed by surface sand-blasting and cleaning with a damp cloth (Figure $7 \mathrm{~b}$ ). The purpose of the holes were to increase the interface bonding. The epoxy bonding agent was applied at the prepared surface, ensuring all holes were properly filled. The plate was attached to the resin, and a paint roller used to create pressure until the epoxy sipped from the edges of the plate, ensuring a good bonding. The access resin was removed, and the plates were protected until they hardened at three days.

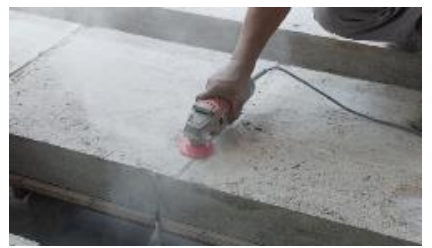

a) 2-4 mm Grinding

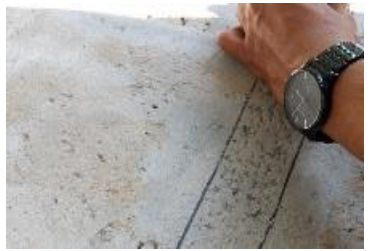

b) 3-5 mm Holes at the Surface
Figure 7. Surface Preparation for CFRP Placement

\section{Results and Discussion}

\section{Load Carrying Capacity and Serviceability}

Table 2 presents the test results of specimens under a monotonic incremented loading.

Where $P_{\text {crack }}$ is the load level at which first cracking in the concrete occur, $P_{\text {yield }}$ is the load that was recorded at first yielding of the tension steel and $P_{\max }$ denoted the ultimate load carrying capacity of the specimen. The ratio of each specific load was compared to the conventional, control element (BC) to clarify and

Table 2. Load Responses

\begin{tabular}{|c|c|c|c|c|c|c|}
\hline \multirow{2}{*}{ Specimens } & \multirow{2}{*}{$P_{\text {crack }}(\mathrm{kN})$} & $P_{\text {crack }}$ & \multirow{2}{*}{$P_{\text {yield }}(\mathrm{kN})$} & $P_{\text {yield }}$ & \multirow{2}{*}{$P_{\max }(\mathrm{kN})$} & \multirow{2}{*}{$\frac{P_{\max }}{P_{B C(\max )}}$} \\
\hline & & $\overline{P_{B C(\text { crack })}}$ & & $\overline{P_{B C(y i e l d)}}$ & & \\
\hline $\mathrm{BC}$ & 29.0 & 1.00 & 92.3 & 1.00 & 116.9 & 1.00 \\
\hline BP1 & 40.9 & 1.41 & 135.6 & 1.47 & 149.8 & 1.28 \\
\hline BP2 & 43.4 & 1.49 & 143.4 & 1.55 & 154.7 & 1.32 \\
\hline
\end{tabular}


analyze the increase in load due to the presence of the external reinforcement (BP1) and additional anchorage (BP2).

The results suggest that the combination of shear and flexure reinforcement improved the ultimate loadcarrying capacity of a member at ultimate up until $28 \%$. This was confirmed by previous researchers [911]. The anchoring of CFRP plates resulted in an increase of $32 \%$. The confinement due to end bearing contributed $4 \%$ to the ultimate load carrying capacity. The loading at stages of first concrete cracking and tension steel yielding also intensified, following a similar pattern to the ultimate load strengthening effect. The cracking load was little influenced by the plate anchoring since the strain levels at the interface were at this stage not influenced by the presence of the confinement, but the yield load was pronouncedly affected, since the anchoring controlled the curvature of the beam.

Table 3 presents the ultimate deflection ratio relatively to the length of the member. It is clearly seen that the external reinforced specimen had a better serviceability performance. The CFRP reinforced members $\mathrm{BP} 1$ and $\mathrm{BP} 2$ had almost half the ultimate deflection when compared to BC.

Table 3. Vertical Deflection Responses

\begin{tabular}{ccc}
\hline Specimens & $\Delta(\mathrm{mm})$ & $\Delta / L$ \\
\hline $\mathrm{BC}$ & 20.5 & $1 / 112$ \\
$\mathrm{BP} 1$ & 12.8 & $1 / 180$ \\
$\mathrm{BP} 2$ & 11.5 & $1 / 200$ \\
\hline
\end{tabular}

\section{Failure Mode}

All specimens were predesigned to behave as underreinforced members, failure is due to tensile reinforcement yielding. Further, the failure mode was predetermined to be in flexure. The ultimate shear load was designed to be significantly higher compared to the ultimate flexure load. The failure modes of all members are shown in Figure 8.

The member's primary crack of specimen BC occurred at mid-span, in the extreme concrete tension fiber. The increment load widened the cracks that vertically propagated towards the neutral axis of the section. Secondary cracks started to form adjacent to the primary crack, at an almost similar horizontal distance (Figure 8a). At the intersection between web and flange, the direction of secondary cracks deviates with a typical 45-degrees angle, signifying that the reduction in section-width shifted the crack to shear characterized failure. Succeeding the extensive steel yielding, the concrete in the compression area crushed.

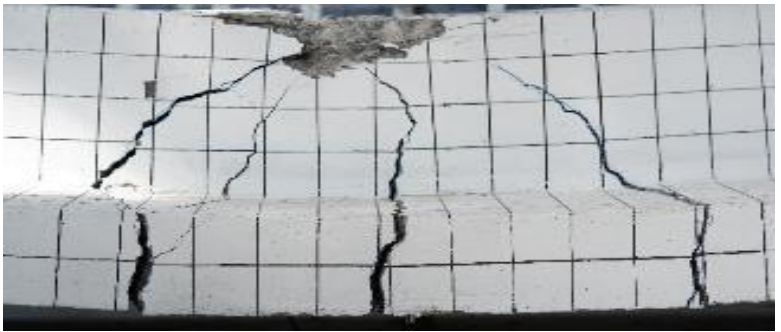

a) Conventional Beam BC

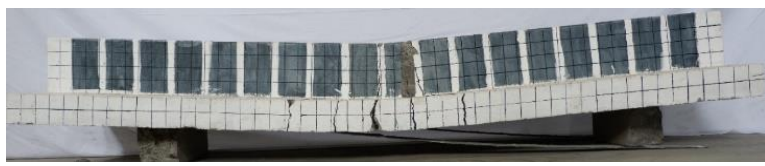

b) Specimen BP1

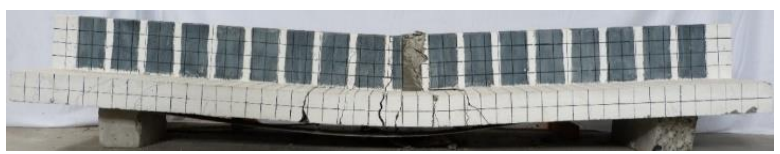

c) Specimen BP2 with Additional Anchoring

Figure 8. Illustrations of Failure Modes

The first crack of both specimens BP1 and BP2 occurred at mid-span, comparable to member BC. Further, the load increment resulted in the yielding of tensile reinforcement. Multiple secondary cracks, more evenly distributed compared to BC, started to form in the flange. This behavior was perceived for both BP1 and BP2 (Figure 8b and 8c). The secondary cracks propagated towards the neutral axis, slightly deflecting into shear cracks at the conjunctions of flange and web. Progressive loading resulted in interface failure for $\mathrm{BP} 1$, starting at longitudinal extremities of the plate (Figure 9a). The failure was characterized by concrete shear-rupture due to high shear-strain disparities. The CFRP plate lost their remaining bond in the interface. Under advanced loading, shear cracks infiltrated the shear reinforcement interface and the bond between the epoxy and the concrete was broken. The sheet was sheared vertically, underneath the de-bonded sheet, large inclined cracks were observed (Figure 9b).

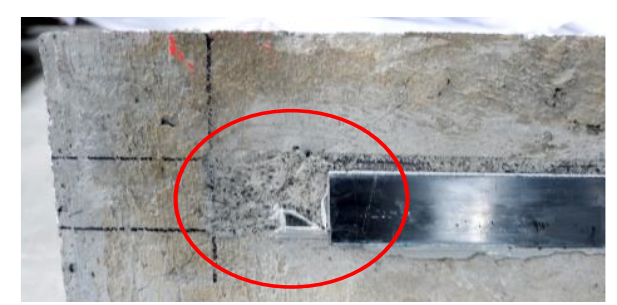

a) Bond Loss in the Plate-to-concrete Interface (BP1)

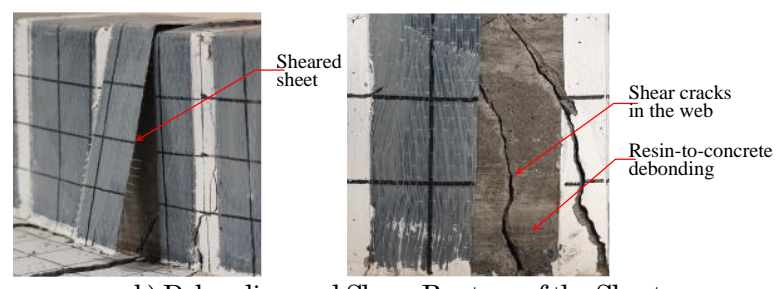

b) Debonding and Shear Rupture of the Sheets

Figure 9. Failure Mode of BP1 
Based on these test results, an attempt was made to enhance the CFRP plate bond at the far ends of the beam by confining the interface strain differentiation between the concrete in tension and CFRP in compression (BP2). The bearing force transferred from the beam to the supports prevented the plate from sliding, as what occur at BP1. This method resulted in rupture of the CFRP plates at mid-point (Figure 10a). The crack-widths at failure was relatively small but more pronounced in number, as compared to BC. Typical to BP2 was the formation of shear-flexure cracks in the flange (Figure 10b). The plate endanchorage magnified the flexure capacity such that the shear capacity in the flanges reached its ultimate.

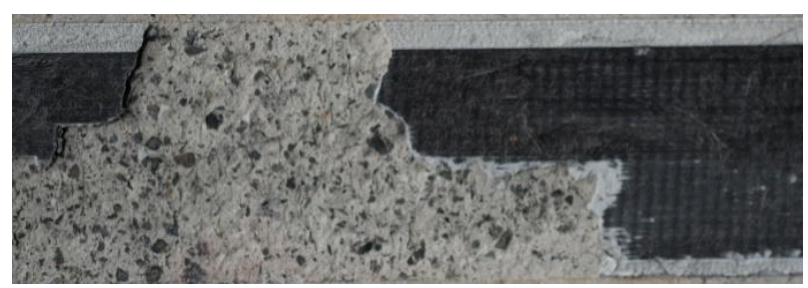

a) CFRP Plate Rupture of BP2

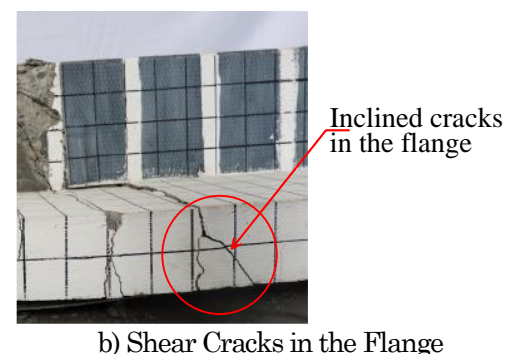

b) Shear Cracks in the Flange

Figure 10. BP2 Failure Details

\section{Analysis and Evaluation}

The test results concluded that the combination of CFRP external reinforcement in shear and flexure could effectively improve the load-carrying capacity of a member in bending. The capacity of a T-section subjected to maximum bending moments and shear increased around $30 \%$ at ultimate, regardless of the presence of CFRP plates end anchorage.

The deformation was reduced by around $40.6 \%$ when compared to the conventional member, underlining that the reinforcement also enhanced the member stiffness. As a result, the crack propagation was moderate and multiple cracks were distributed in the midspan's vicinity with significantly narrower crackwidths. These are benefits in terms of serviceability and crack control with respect to steel corrosion.

Examining the interface between the CFRP plate and concrete, it was concluded that strain disparities were induced as a result of a condition where the extreme concrete layers are in tension and the CFRP is in compression (Figure 11). The strain differences were eminent at the far ends, since the concrete turned out to be the weakest element of this integrated system, the concrete ruptured in shear (BP1). From this phenomenon, it is well demonstrated that the concrete compression strength plays a most important role in the behavior of such externally reinforced members. The CFRP to resin bond is a function of its overall bond area; when the concrete ruptured at the far ends, the bond-length drastically diminished, resulting in debonding in the remaining interface. A well-proven fact of this hypothesis is when the far ends of the FRP plates were anchored to the concrete for BP2, the failure was characterized by CFRP plate rupture at center point followed by concrete shear rupture.

The existence of secondary shear cracks in the CFRP anchored element BP2 points to manufacturing imperfection since analytical calculations disclosed that the shear capacity in this area was theoretically above the load-induced stresses. A special method to treat the concrete surface prior to sheet placement was studied [14], and it was concluded that the methods as advised by the CFRP producer were not sufficient to prevent the sheets from debonding at advanced strain levels. In calculations, a 20\% increase in concrete strength due to the confining effect was incorporated into the analysis; debonding of shear reinforcement also mend losing this confinement.
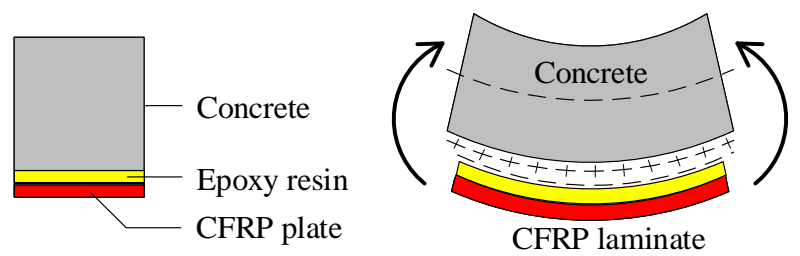

Figure 11. Strain Mechanism in the Interface

\section{Conclusion}

Two types of flexural T-sections were experimentally investigated; the first was a conventionally underreinforced member, and the second an externally reinforced member using CFRP sheets in shear, and plates in flexure. The shear reinforcement was situated in a u-configuration on the web, while the plates were attached to the extreme concrete tension fibers. To analyze the response of plate-anchoring, one specimen was mechanically bonded to the concrete at the plate's far ends. The load-carrying capacity, vertical deflection, and failure mode was studied and it was concluded that:

The system significantly improved the overall performance of the member. The load-carrying capacity and serviceability were raised, and cracking was more evenly distributed in combination with reduced crack-width formation; the latter resulted in an indirectly better protection against corrosion. 
The interface has a paramount position in the failure mechanism of this system. The majority of failure was detected in this interface, either due to concrete rupture, debonding, or CFRP rupture. Anchoring the CFRP plates has an inconsequential impact on the beam's performance, while the anchoring method is costly and time-consuming. Other methods to improve the concrete surface quality for better bonding could be accessed, this also counts for the CFRP sheets in shear. Precautionary care has to be taken during the design of CFRP externally reinforced members with improved interfaces that the failure mode remains in flexure.

The concrete strength places an important part in the overall performance of externally strengthened members. The case of premature shear failure in the flange was detected due to an imperfect concrete placement and or curing. In the field, the flanges are situated on top and are therefore exposed to premature evaporation and external influences. It is advised to throughout determining the concrete strength at this location, prior to design.

\section{Acknowledgments}

The authors would like to acknowledge PT. SIKA Indonesia, the Structural and Material Laboratory of the Diponegoro University and the research cooperation between Nihon University in Japan, Atma Jaya University in Yogyakarta and Diponegoro University in Semarang.

\section{References}

1. Pešic, N. and Pilakoutas, K., Tensile Stress-strain Relaxation as a Failure Precursor for FRPStrengthened RC Beams, Composite Structures, 125, 2015, pp. 530-541, doi: 10.1016/j.compstruct. 2015.01.052.

2. Ha, S.K., Khalid, H.R., Park, S.M., and Lee, H.K., Interfacial Crack-induced Debonding Behavior of Sprayed FRP Laminate Bonded to RC Beams, Composite Structures, 128, 2015, pp. 176-187, doi: 10.1016/j.compstruct.2015.03.040.

3. Hadjazi, K., Sereir, Z., and Amziane, S., Creep Response of Intermediate Flexural Cracking Behavior of Reinforced Concrete Beam Strengthened with an Externally Bonded FRP Plate, International Journal of Solids and Structures, 94-95, 2016, pp. 196-205, doi: 10.1016/j.ijsolstr. 2016.04.012.

4. Liu, X., Jiang, J., Wang, G., Wang, J., and Xu, R., Debonding Analysis of Curved RC Beams Externally Bonded with FRP Plates using CZM, Engineering Structures, 205, 2020, p. 110103, doi: 10.1016/j.engstruct.2019.110103.
5. El-zeadani, M., Rashid, R.S.M., Amran, Y.H.M., Hejazi, F., Jaafar, M.S., Alyousef, R., Alabduljabbar, H., Case Studies in Construction Materials Analytical Mechanics Solution for Measuring the Deflection of Strengthened RC Beams Using FRP Plates, Case Studies in Construction Materials, 11, 2019, p. e00272, doi: 10.1016/j.cscm.2019.e00272.

6. Zhou, Y., Wang, X., Sui, L., Xing, F., Wu, Y., and Chen, C., Flexural Performance of FRP-Plated RC Beams Using H-Type End Anchorage, Composite Structures, 206, 2018, pp. 11-21, doi: 10.1016/j. compstruct.2018.08.015.

7. Fu, B., Tang, X.T., Li, L.J., Liu,F., and Lin, G., Inclined FRP U-Jackets for Enhancing Structural Performance of FRP-Plated RC Beams Suffering from IC Debonding, Composite Structures, 200, 2018, pp. 36-46, doi: 10.1016/j.compstruct.2018. 05.074 .

8. Zhang, S.S., Yu, T., and Chen, G.M., Reinforced Concrete Beams Strengthened in Flexure with Near-Surface Mounted (NSM) CFRP Strips : Current Status and Research Needs, Composites Part $B, 131,2017$, pp. 30-42, doi: 10.1016/j.compositesb.2017.07.072.

9. Bocciarelli, M. and Pisani, M.A., Survey on the Interface Behaviour in Reinforced Concrete Beams Strengthened with Externally Bonded FRP Reinforcement, Composites Part B, 118, 2017, pp. 169-176, doi: 0.1016/j.compositesb.2017. 02.047.

10. Bennegadi, M.L., Hadjazi, K., Sereir, Z., Amziane, S., and El Mahi, B., General Cohesive Zone Model for Prediction of Interfacial Stresses Induced by Intermediate Flexural Crack of FRP-Plated RC Beams, Engineering Structures, 126, 2016, pp. 147-157, doi: 10.1016/j.engstruct.2016.07.030.

11. Ozbakkaloglu, T., Fang, C., and Gholampour, A., Influence of FRP Anchor Configuration on The Behavior of FRP Plates Externally Bonded on Concrete Members, Engineering Structures, 133, 2017, pp. 133-150, doi: 10.1016/j.engstruct.2016. 12.005.

12. Ceroni, F., Ianniciello, M., and Pecce, M., Bond Behavior of FRP Carbon Plates Externally Bonded over Steel and Concrete Elements : Experimental Outcomes and Numerical Investigations, Composites Part B, 92, 2016, pp. 434-446, doi: 10. 1016/j.compositesb.2016.02.033.

13. Nguyen-minh, L., Phan-vu, P., Tran-thanh, D., Phuong, Q., and Truong, T., Flexural-Strengthening Efficiency of CFRP Sheets for Unbonded Post-Tensioned Concrete T-Beams, Engineering Structures, 166, 2018, pp. 1-15, doi: 10.1016/j.engstruct. 2018.03.065.

14. Tudjono, S., Han, A.L., and Gan, B.S., An Integrated System for Enhancing Flexural Members' Capacity Via Combinations of the Fiber Reinforced Plastic Use, Retrofitting, and Surface 
Treatment Techniques, International Journal of Technology, 1, 2018, pp. 5-15, doi: 10.14716/ijtech. v9i1.298.

15. Tudjono, S., Han, A.L., and Hidayat, B.A., An Experimental Study to the Influence of Fiber Reinforced Polymer (FRP) Confinement on Beams Subjected to Bending and Shear, Procedia Engi- neering, 125, 2015, pp. 1070-1075, doi: 10.1016/j. proeng.2015.11.164.

16. Sapulete, C.A., Studi Eksperimental Pengaruh Perkuatan Lentur Fiber Reinforced Polymer Rod pada Balok dan Efektivitasnya, Master Thesis, Master Program Civil Engineering, Diponegoro University, Semarang, 2018. 